\title{
DISCLAIMER
}

This repon was prepared as an account of work sponsored by an agency of the Unjted States Government. Neither the United States Government nor any agency thercof, nor any of their employees, makes any wartanty, express or implied, or assumes any legal liability or responsibility for the accuracy, completeness, of usefulness of any information. apparatus. product. or process disclosed, or represents that its use would not infringe privately awned rights. Refercroe herein to any specific commercial product. process, of service by trade name, teademark. manufacturer, or otherwise does not necessarily constitute or imply its endorsement, iecommendation. or favoring by the United States Guvernment or any agency thereof. The views and opinions of authors expressed herein do not necessarily state or reflect those of the United States frovernment or any agency thereof.

\section{Plan for Metal Barrier Selection and Testing for NNWSI}

\author{
William G. Halsey
}

R. Daniel McCrigh:

Revision 0

Manuscript Date 10/20/87

January 1988 
Plan for Metal Barrier

Selection and Testing for NMWSI

Table of contents

1.0 Purpose and objectives . . . . . . . . . . . . . . 1

1.1 Regulatory Requirements . . . . . . . . . . . . 1

1.2 Metal Barrier Testing Activitics

Grouped by SCP Investigations ............... 2

1.3 Activity Groumings for SIP . . . . . . . . . . . . . . 6

1.4 Information flow...............8

2.0 Rationale for selected Activities

and Quality Assurance Level Assignments . . . . . . . . . .12

2.1 Introcuction . . . . . . . . . . . . . . . . 12

2.2 Metal Barrier Selection process . . . . . . . . . . 13

2.3 Metal Barrier Performance Mocieling . . . . . . . . . . 15

2.4 Netal Barrier Performance Testing ............ . I9

2.5 Design Properties of Metal Barrier . . . . . . . . . . .21

3.0 Description of Tests, Models, and Analyses . . . . . . . . .23

3.1 Introduction . . . . . . . . . . . . . . . . . 23

3.2 yutal Barrier Selection Process . . . . . . . . . . .23

3.2 .1 Degradation mode surveys ............. 23

3.2.2 Establishment of criteria

for metal barrier selection ........... . .24

3.2.3 Metal barrier selection............. . 26

3.3 Metal Barrier Derformance Kodeling . . . . . . . . . . 27

3.3.1 Development of models for degradation modes,

mechanical properties, and microstructure . . . . .27

3.3.2 Integration of models for selected material . . . .29

3.3.3 Performance parameter studies . . . . . . . . 29

3.3.4 Validation of models ..............29

3.4 Hetal Barrier Performance Testing . . . . . . . . . . 30

3.4.1 Experimental technique develoqment ........ . 30

3.4.2 Parametric studies of metal degradation

and microstructure .............. . . . . . . .

3.4.3 Development of plans for license application

support tests..................33

3.4.4 License application support tests . . . . . . . . 34

3.5 Design Properties of Metal Barrier ............... 35

3.5.1 Coordination with package design . . . . . . . 35

3.5.2 Determination of mechanical and microstructural

properties of metal ..............36

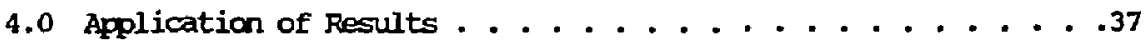

5.0 List of Test Plans to support this Investigation Plan . . . .39

6.0 History of Metal Barrier Candidate List . . . . . . . . 40

7.0 Annotated Reference Iist . . . . . . . . . . . . . 42 


\title{
List of Acromps
}

\author{
AISI - American Iron and Steel Institute \\ ASTM - American Society for Testing and Materials \\ CDA - Copper Development Association \\ CFR - code of Federal Regulations \\ DOE - Department of Energy \\ ESCA - Electron scattering for chemical analysis \\ ETS - Enviromental Irpact Statement \\ FY - Fiscal Year \\ IN - Information Need \\ LUNL - Lawrence Livermore National Laboratory \\ NACS - National Association of Corrosion Engineers \\ NNASI - Nevada Nuclear Waste Storage Investigations \\ NRC - Nuclear Regulatory Camission \\ MMP - Muclear Waste Management Program \\ OCFW - Office of Civilian Radioactive Waste Kanagement \\ QA - Qulity assurance \\ QAPP - Quality Assurance Program Plan \\ soc - Stress corrosion cracking \\ SCP - Site Characterization Plan \\ SIP - Scientific Irvestigation Plan \\ WRS - Hork breakdown structure
}




\section{Preface}

The Department of Energy's Nevada Nuclear Haste Storage Investigations (NRWSI) Project is evaluating a site at Yucea Mountain in Nevada as a geological repository for the storage of high-level nuclear waste. The Nuclear Waste Management Projects (MMP) at Lawrence Iivermore National Laboratory (LINL) has the responsibility for design, testing, and performance analysis of the NWMSI waste packages. One portion of this work is the selection and testing of the material for container construction. The anticipated container design is for this material to be a corrosion resistant metal called the metal barrier.

This cocament is the publication version of the Scientific Investigation Plan (SIP) for the Netal Earrier Selection and Testing Task. The SIP serves as a formal planning document for the investigation and is used to assign quality assuranoe levels to the activities of the task. This document is an informal version for information distribution and has the sections on ischedule and Milestones' and the 'Quality Assurance Ievel Assignment Sheets' removed. 


\section{Plan for Metal Barrier \\ Selection and Testing for NWwSI}

\subsection{Punpose and Objectives}

\subsection{Requlatory Requirements}

The purpose of the work outlined in this plan is to determine the rate at which the metal barrier will be degraded by its interaction with the repository envirorment and to project these determinations over the time scale of interest in demoristrating first, the contaiment of the waste, and second, the controlled release of radioisotopes. Several degradation mechanisms of the metal barrier are possible, and a significant effort in this plan is directed toward providing information which will be used in determining which of the several degradation mechanisms will gperate in the repository environment. In addition, several candidate meial barrier materials are presently under consideration, and a large effort in this plan is directed toward providing information that will be used as the basis in selecting the material for the license application waste package derign. A brief discussion of how the current list of candidate materials developed can be found in Section 6.0.

The information generated in this plan will be used to show that the waste package meets the contairment requirements of $10 \mathrm{CFR} 60.113$. In addition, the information is used, in part, to demonstrate the waste package retrievability requirements in 10 CFR 60.111 (b). Along with information generated in the plans for waste form testing (both spent fuel and glass waste forms), the information from this plan will serve as a component in determining the source term for repository performance assessment modeling. Results from this work will provide the waste package environment task with information describing critical enviromental parameters and how they affect the container material performanoe, thus indicating areas to be examined during the exploratory shaft investigations. Furthermore, the information will contribute, in part, towara estimating the source term in the calculation of long term cumulative

releases. These calculations form part of the estimates of releases to the acossible enviroment required for $40 \mathrm{CFR} 191.13$ (amulative releases after 10,000 years) and for campletion of the site evaluation process required for 10 CFR 960.3-1-5 (amulative releases after 100,000 years).

The Netal Barrier Selection and Testing Scientific Investigation Plan addresses the following SCP information needs:

Issue 1.4: will the waste package meet the performance objective for ontaimment as required by 10 CFR 60.113?

IN 1.4.1 Waste package design features that affect the performance of the container.

IN 1.4.2 Material properties of the container.

IN 1.4.3 Scenarios and models needed to predict the rate of degradation of the container material

Through imput to the above information needs, the work covered by this plan will also provide data used to address information needs 1.4 .4 and 1.4 .5 (Performance assessment for contairment objectives) : 1.5.4 and 1.5.5 (Performance assessment for controlled release objectives); 1.10 .1 and 1.10.2 
(Waste package design), 2.6.1 (Preclosure design criteria concerned with materials, handling, and identification), 4.3.1 (Waste package production technology), and 4.5.1 (Waste package costs).

\subsection{Netal Barrier Selection and Testing Activities Grouped by SCP Investications}

The irvestigations and activities of the three 1.4 Information Needs (IN) from the Site characterization Plan (SCP) are grouped as follows: (1) IN 1.4.1 is concerned with characterization of the as-fabricated and as-emplaced waste package container; (2) In 1.4.2 is concerned with characterization of the waste package container after elplacement (hence the emphasis on different degradation modes); and (3) $\mathrm{NN} 1.4 .3$ is concerned with modeling to predict the rates of these different degradation modes.

There is not a che-to-ane correspondence between the full set of investigations and activities listed under the above INs and the activities described in this Scientific Investigation Plan (SIP) for the Metal Barrier Selection and Testing Task (TRS 1.2.2.3.2). This situation oocurs because the 1.4 Issue and subsumed Information leeds exist to resolve contairment issues, while the content of this SIP is addressed specifically to the metal barrier, which is not the only engineened contairment barrier. Thus, the investigations and activities associated with the properties of a ceranic lirer in IN $1.4 .1,1.4 .2$ and 1.4 .3 as an altemative waste parkage design are discussed in the SIP for "other materials" (WBS 1.2.2.3.3). The Matal Barrier SIP is centered around laboratory testing, develogment of models to predict resistance to various degradation modes, and characterizing the properties of the candidate metals and alloys as materials of construction. The characteristics of the processes for actually fabricating the container and constructing the waste package are, therefore, discussed in the SIP for "Design, Fabrication, and Prototype Testing" (WBS 1.2.2.4). Thus, same of the activities discussed in IN 1.4.1 more logically fall into that SIP. There is the dovious need for close co-operation between the activities for these different wAS element SIPs, hence the identification of integration activities between the appropriate plans.

Although the Netal Barrier SIP has several features analogous to those found in the SIPs for characterizing the spent fuel and the borosilicate glass waste forms (WBS 1.2 .2 .3 .1 ), there are two unique features of the Netal Barrier SIP that distinguish it and influence the course of the planned activities. These features are:

(1) the process for specifying which of the several candidate materials will be selected for the license application design. In order to arrive at a defensible selection process, many of the activities must be concucted in parallel for the different candidate materials. This means that a muber of activities will be carried out to a level to provide needed information for the selection process, but that the full suite of activities will be coupleted only for the candidate material that is selected for the license application designi.

(2) much information on characterizing the candidate metals cames from the open literature and from various commercial sources, including potential vendors for the container material. Ttre information often derives frum non-ruclear applications. Unlike informiation on other materials that are part of the waste package (e.g. borosilicate glass or uranium dioxide fuel elements), these sources of information are largely outside the control of the DOE, NRC, or other govermmental agencies. 
This has important quality assuranoe implications with regard to the number of possible sources of information and the campleteness of the docmentation. Because a strong argument for the selected container material will be built on previous and suocessful uses of the material in other engineering applications, it is vital to use available information on performance of the candidate mater: vls. Therefore, a considerable effurt is involved in determining what previously published information in the tectunical literatume is relevant and applicable to the present work.

\section{MEIRL BARRIER WORK OUITINE ERCY SCP}

Note: The asterisked $(*, * *)$ investigations and activities from the SCP (as listed below) are not discussed in the Metal Barrier selection and Testing SIP. Discussions of these will be found in the SIP for Design, Fabrication and Frototype Testing (itens marked *), and in the SIP for Other Materials (items marked $\star *$ ).

Info InvestiNoed cation Activity

1.4.1 Waste package design features that affect the performance of the container

1.4.1.1 Integrate design and materials informatian (metal container)

1.4.1.1.1 Mechanical properties

1.4.1.1.2 Microstructural properties

*1.4.1.1.3 Prysical properties

*1.4.1.1.4 State of stress in the container

*1.4.1.1.5 Characterization and inspection of weld integrity

*1.4.1.1.6 Characterization of the container surface

**1.4.1.2 Integrate design and materials information (metal container with a ceramic liner)

$\star \star 1.4 .1 .2 .1$ Feasibility evaluation of fabricating a ceramic-lined waste package

1.4.2 Material properties of the container

1.4.2.1 Selection of the container material for the license application design

1.4.2.1.1 Establishment of selection criteria and their weighting factors

1.4.2.1.2 Material selection 
Info Irvesti-

1.4.2.2 Degradation modes affecting candidate copper-base container materials

1.4.2.2.1 Assessment of degradation modes in copper-base materials

1,4.2.2.2 Netallungical aging and phase stability

1.4.2.2.3 Low temperature oxidation

1.4.2.2.4 General aqueaus corrosion

1.4.2.2.5 Hyodrogen entry and enbrittlement

1.4.2.2.6 Pitting, crevice, and other localized attack

1.4.2.2.7 Stress corrosion cracking

1.4.2.2.8 Other potential degradation modes

1.4.2.3 Degradation modes affecting candidate austenitic container materials

1.4.2.3.1 Assessment of degradation modes in austenitic materials

1.4.2.3.2 Metallurgical aging and phase transformations

1.4.2.3.3 LOA temperature oxidation

1.4.2.3.4 General aqueous corrosion

1.4.2.3.5 Intergranular attack and intergramlar stress corrosion cracking

1.4.2.3.6 Hydrogen entry and embrittlement

1.4.2.3.7 Pitting, crevice, and other localized attack

1.4.2.3.8 Transgranular stress corrosion cracking

1.4.2.3.9 Other potential degradation modes

$\star \star 1.4 .2 .4$ Degradation modes affecting the ceramic liner

$\star \star 1.4 .2 .4 .1$ Assessment of the degradation modes affecting the ceramic liner

$\star \star 1.4 .2 .4 .2$ Laboratory test plan for ceramic liner materials 
1.4.3 Soenarios and models needed to predict the rate of degradation of the container material

1.4.3.1 Hodels for ogper and oopper alloy degradation

1.4.3.1.1 Metallurgical aging and phase stability

1.4.3.1.2 Iow temperature axidation

1.4.3.1.3 Gereral aqueous corrosion

1.4.3.1.4 Hydrogen entry and embrittlement

1.4.3.1.5 Pitting, crevice and other localized attack

1.4.3.1.6 stress corrosicn cracking

1.4.3.1.7 Other potential degradation modes

1.4.3.2 Models for austenitic material degradation

1.4.3.2.1 Hetallurgical aging and phase transformations

1.4.3.2.2 Low temperature oxidation

1.4.3.2.3 General aqueous corrosion

1.4.3.2.4 Intergranular attack and intergranular stress corrosion cracking

1.4.3.2.5 Hydrogen entry and embrittlement

1.4.3.2.6 Pitting, crevice, and other localized attack

1.4.3.2.7 Transgranular stress corrosion cracking

1.4.3.2.8 Other potential degradation modes

**1.4.3.3 Models for ceramic material degradation

**1.4.3.3.1 Dissolurican of alumina

**1.4.3.3.2 Loss of fracture taughness

At the present time, the NWWSI Project is considering the technological feasibility of producing a ceramic-lined metal container as a waste package design option. In such a case, the lang-term container performance function would largely be taken by the ceramic material with the function of the metal. to be largely limited to the handling and emplacement cperations. If the Project were to chocse this option, then much of the work discussed in this SIP would be truncated. 


\subsection{Activity Groupings for the Metal Barrier Selection and Testing SIP}

For this plan, certain of the above activities group together naturally because of parallel efforts (e.g. model develogment for the various degradation modes in each alloy system; laboratory test plans corresponding to each degradation mode) and because these grouped activities have the same determined quality assurance levels. These groupings define the activities of the retal Barrier selection and Teeting task as described in this SIP.

Metal Barrier selection Prooess (see sections 2.2 and 3.2)

E-20-13 Degradation mode surveys

E-20-15 Establishment of criteria for metal barrier selection

E-20-15 Metal barrier selection

Ketal Barrier Performance Yodeling (see sections 2.3 and 3.3)

E-20-16 Develogment of models for $\dot{v}$ gradation modes, mochanical properties, and microstructure

E-20-20 Integration of models for selected material

E-20-21 Performance parameter studies

E-20-25 Validation of model

Netal Barrier Performanoe.Testing (see sections 2.4 and 3.4)

E-20-17 Experimental tectunique develoquent

E-20-18 Paranetric studies of metal degradation and microstructure

E-20-22 Develogment of plans for license application support tests

E-20-23 License application apport tests

Desion Properties of the Natal Barrier (see sections 2.5 and 3.5)

E-20-14 Coondination with package design

E-20-24 Determination of mechanical and miccostructural properties of metal

The nubers assigned to these thixteen activities are in approximate chronological sequence of occurance. 
The following list is a cross reference between the activities from the ScP Information Needs of Issue 1.4 and the activities described in this plan. The titles of the activities are given in the preceding lists. There is not a one-to-one correspondence, and not all of the activities fran this plan ace included, because E-20-13 is a preaurssor to other work in this plan and does not directly correspond to activities in the Information Needs.

SIP Sections SIP Activity Number SCP Activity Number

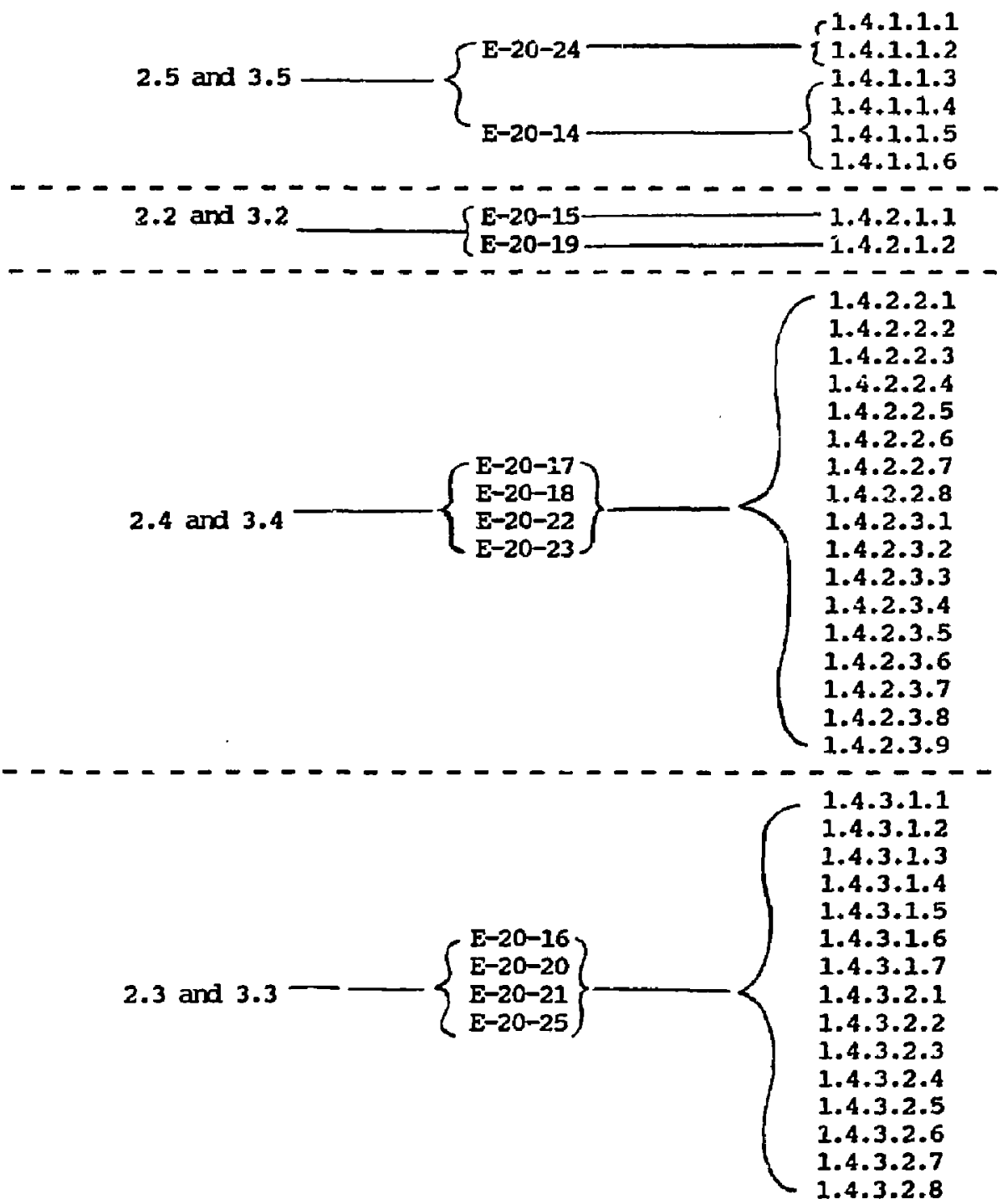




\subsection{Inforation Flow}

The goals of wetal barrier selection and testing are to select one (or two) material (s) from the present list of six candidates that will be used for advanced waste package design work and to test the selected material (s) to provice azoquate data for models concerning the lang-tem chemical and petallurgical stability of the material(s) under anticipated conditions and a reasconable muber of credible but unanticipated conditions. The present list of candidates are AISI 304L, AISI 316L, and Alloy 825 in the "austenitic" fanily and $\cos 102, \cos 613$, and $\cos 715$ as copper-base materials.

As illustrated in Pigure 1, information fram sances outside this plan is required for several of the activities of this plan. These autside sources, labeled as 'Information Irput', include previously published infonmation in the technical literature on the dagradation modes of the candidate materials, previaus results fron NiSI-spansored wok on metal barrier invesigations, MisI-Epansored work on the near-package envirarment, work on otiner material C panents of the waste package and engineered barriers (including borehole liners, cenents, and grouts), performanoe assessment soenarios, and geochemical modeling (to derive the physical and cheaical enviroment surrounding the waste paclage container). Another ingut will be the use of the $503 / 6$ code in the selection process.

Another saunce of "infocmation" from atside the Hetal Barrier selection and Testing task is in the boo labeled "Nodking Canstraints" in Figure:These include the performance requirenents established by the various Federal regulations, the assesenent of the repository enviranent before and after enclace ent of the vaste packages (including the DOE-ARC approved definitions of antivipated and unanticipated processes and events), and the preliminary design require ents (Canceptural Design Level). A unique feature of the ruoca Wountain site is that the repository will be located in the unsaturated zone, above the permanent water table. An ipportant advantage of this location is that sane of the emircnental features can be "engineered" to create more favorable conditions to prolang the container lifetime. A good exalple of engineering the envirar ent is to maintain the te perature at the cartainer surface above the unrestrained boiling point of water for as long as possible on a large wajority of the reste paciages. This is done by considering the heat load per package and configuring the repository with a suitable heat load per unit area. As part of the RissI strategy to demonstrate the containment objectives, the waste peckage container (netal barrier), the waste form, and the engineered envirar ent are jointly considered as the "containuent barrier". This strategy is are fully explained in the discussion of the resolution of Issue 1.4 in Chapter 8 of the SCP. The regulatory requirements, the waste pacionge design requirenents and the repository ervirament assessment (including ways to engineer the envirurmant to emance the raste package performanol are viewed as constraints, because they establish some limits on what wust be accauplished in the activities in this plan. 
As seen in Figure 1, the activities in this plan are naturally divided into two parts, separated by the selection step. Up until this selection the work covers all six initial candidate metals, including three austenitic alloys and three copper-base alloys. The three austenitic allojs are iron-base (stainless steels) and nickel-base (alloy 825) with the prinary phase (austenite) being a face-centered cubic structure in all alloys. The copper-base alloys are also face-centered cubic in structure. All of these materials are hatdened by solute additions or by cold work; all of the materials possess considerable inctility over a wide range of temperatumes. These materials are widely used in industrial and structural applications; a major reason for their use is good corrosion resistance in mary lifferent kinds of enviranments, although the candidate waterials differ on the limits of enviranental conditions in winch they can be sucoesfully used. In the most general considerations of materials, all of the candidate materials are reascnably simple in wicrostructure (no intentional secondary phases for hardening), although there are important differences anong the candidates on this point. While a high-purity ooper is one of the candidate materials, this material, too, can be regarded as a dilute alloy. In fact, it may be desirable to add or retain some decoxidizing elements (in the 100's to 1000's pgm range) to make the material more readily weldable and to prevent formation of internal copper cxides. Thus the words "alloy" and "material" are used interchangably and synonymously in this SIP.

Criteria for selecting the material(s) or alloy(s) for use in che final design mut be decided upon, and an information base prepared to support these criteria. This information base includes conrosion models, corrosion data, existing literature, and evaluations from authoritative sources in the metals industry. After the selection of the alloy(s), the activities concentrate on generating a validated model for the material(s)

performance in the repository envirament. This model will be confirmed by laboratory tests. In effect, those elenents of the plan above the "selection" activity in Figure 1 are directed towand making that selection. Those activities below the "selection" are directed toward validation of the long term performance model of the metal selected. When this task is camleted, the validated model will becone a portion of the overall repository perfocmance assessment model used to support advanoed designs and the license application. 
Two other waste package tasks that have substantial interaction with the Metal Barrier Selection and Testiry Task are shown in Figure 1: the Waste Package Desig2, Fabrication and Prototype Testing Task and the Waste Package Performance hssessment Task. There must be interaction between the Metal Barrier Selection and Testing work and the work in these two tasks to provide conndination as the work evolves. This is to insume that the metal barrier selected will be campatible with the design and fabrication features being reseancised (and vice versa), and that the degradation models developed in this task will mesh wen needed with the overall performance model. The cutput fram this task will be: 1) the selection of ane (or two) alloys, a description of mechanical and microstructural properties, and performance canfirming tests, provided to the Design Task; 2) validated models to describe the behavior of the material under repository canditions provided to the ferformance Assessment Task.

Information fran soue aditional waste package tasks (not shown explicity in Figure 1) influences the course of activities in the Ketal Barrier selection and Testing Task. To a lesser extent, information from the Ketal Barrier Selection and Testing Task is used in these tasks but does not have a primary influence on the course of work plamed in them. Information about the enviroment noar the container surface comes from the Envirorment Task and is shown in Figure 1 as one of the "Information Inputs" and one of the "Working constraints". The primary conoern is the ervirament outside the container, but in a few instances there is concern about the ervironment inside the container. This information is important in analyzing the degradation modes for the candidate materials. Information derived in the Metal Barrier Task on corrosion of candidate materials influences the Enviroment Task and also the Waste Form Testing Task. Corrosion products formed during the long-term degradation of the container will influence the waste package envircment (particularly if the products are somewhat soluble and can be transported) and Inay cegrade the performance of the waste form. The "compatibility" of the pacirage container and the waste form is proposed as one of the factors in selecting the container material. output fram the Netal Barrier Selection and Testing Task on corrosian product formation is ane of marn factoss that goes into the $123 / 6$ geochemical code, shown in Figure 1 as the Rerformance Assessment Task. 
Figure 1

Metal Barrier Selection and Testing Information Flow

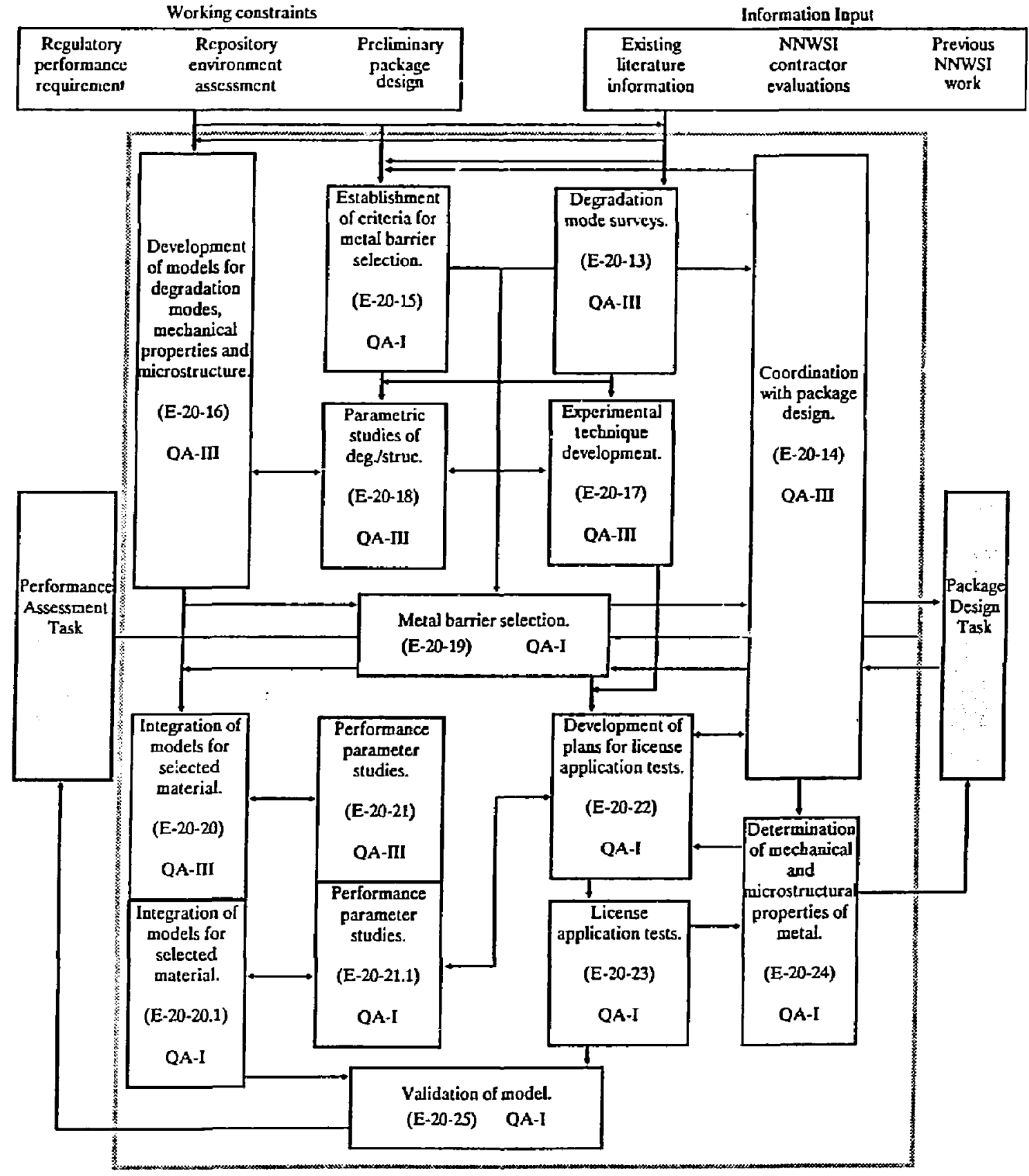




\subsection{Raticnale for Selected Activities and quality Assurance Ievel Assignments}

The rationale for the four work areas and thirteen activities listed in section 1.2, and their $Q$ level assignments are disoussed in this section.

\subsection{Introduction}

The work in this plan is the content of WBS element 1.2.2.3.2 (Metal Barrier Selection and Testing) and is concerned with the long-term models to predict the mechanical and microstructural properties of the container material, and the rates of cocurrence and rates of propagation for the different possible degradation modes. In most cases, the ervirormental, mechanical, and metallurgical factors that cause the different degradation nodes are known from previous experience with the candidate materials, so that the starting point for model develogment cones from observation, measurement and understanding of those environmental, mechanical, and metallurgical factors that influence these degradation modes in the context of the repository setting. Laboratory work is centered around guantifying these degradation modes in the time periods generally available for laboratory testing (periods ranging fram several hours to a few years). The general purpose of this laboratory work is to determine the rates of the different degradation modes as they relate to the physical, chemical, and mechanical properties of the container material and its surnoundings. Confidence is gained in the model develogment by predicting to progressively longer time periods what is expected to occinr and then actuali $i_{1}$ conducting experiments or tests over those time periods to canfirm the prediction. The rationale of this approach is to begin the laboratory activities in more highly aggressive conditions than expected (where the phencmenon under investigation is accelerated to occur in a short period of time) and then to reduce the aggressiveness of the conditions in order to appraach the anticipated enviramental conditions as a limit (where the same phenamenon occurs in progressively longer time periods). As needed, the models are modified in accordance with the results from the laboratory work.

In parallel with modeling and laboratory activities, this task will also select one (or two) materials for advanced study from the preliminary list of candidates. This selection process provides a dividing line between broadbased preliminary screening activities and the detailed final activities proctucing documentation for a license application design metal barrier. As noted above, this task will also interface with two others: waste package design and performance assessment. The intent of these interface activities is to insure that the results of this task are colpatible with the results and requirements of these other efforts, and to keep the effort of this scientific Investigation Plan directed toward the same goals as the other program elements. 


\subsection{Metal Barrier Selection Progess}

These activities describe the process for selecting one or two materials for advanced design and performance testing. A. set of criteria for material or alloy selection is needed to compare candidate materials with one another. An initial set of 'survey papers', each of which assesses the importance of particular degradation modes to a family of alloys, will provide a framework for evaluating the performance of candidates in the selection process. The selection process includes the documentation and review requirements for metal barrier selection.

\section{Activity E-20-13 Degradation mode surveys}

The 'Degradation mode surveys' (E-20-13) are a consolidation of available information related to the expected performance of the two families (copperbase and austenitic) of candidate alloys with respect to each particular mode of degradation (e.g. localized corrosion). The surveys will specifically concentrate on docamentation of data needed to campare degradation rates of the container material over long time periods. The degradation modes are defined as chernical or mechanical processes (and sametimes combinations of these) that penetrate the metal structure and ultimately perforate it. The reason for separating the processes into the different modes is that the penetration follows different propagation patterns. These modes are explained more fully in the parts of chapter 7 and 8 of the sCP dealing with metal barriers and in several texts on corrosion of metals - see Section 7.0 of this SIP.

The rate of perforation of the metal container and the number of containers perforated are important factors in demonstrating the performance of the waste package for containment and of the engineered barrier system for cantrolled release. The goal is to determine for each candidate alloy which degradation modes are insignificant, which are potentially significant, and which appear to limit an alloy in meting the performance objectives. The rationale for this activity is that a great deal of information is available on metal performance, but it must be evaluated and applied to the specific case of a metal barrier in a Yucca Mountain waste container to assess the prospects for repository performance. Thirteen combinations of alloy family and degradation modes have been identified for assessment. Completion of these surveys will provide documented statenents of potential alloy performance, which will serve as the

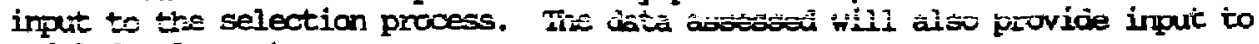
model development.

This activity (E-20-13) will be conducted at of Level III. The ocntainer material selection criteria (E-20-15) and the selection process itself (E-20-19) will be conducted at Level I. However, the survey information that is used in the selection is not directly tied to the license application data, which will be generated after the container material selection. The purpose of the survey information is to guide the work that will be followed once the selection is made. Nuch of the basic information to be used in the survey of degradation modes cones from the open technical literature, which does not have a ga level associated with it. 
The criteria for selection of a metal barrier alloy(s) for advanced work must be developed, reviewed, and approved. Activity E-20-15 'Establishment of criteria for metal barrier selection' is the process of defining those criteria. The rationale for this work is thet a motal barier material cannot properly be chosen until the criteria for selection are established and acoepted by a process of peer review and comment as provided for in the Quality Assurance Program Plan (QAPP) of the Nuclear Waste Management Program (NWPP) .

This activity will be condinted at $Q$ Level I. The reason for this level assigment is that the selected material and the defense of its selection are fundamental bases of the license application data base. The container material selection is also an important project milestone, and its delay would cause consicerable slip in the project schechle. This fact alone would make the material selection and seiection criteria Level II, but the fact that the primary intention of the activity is to provide the reasons for selecting the material for the license application design makes the activity Level I.

\section{activity E-20-19 Metal barrier selection}

'Hetal barrier selection' will be performed in activity E-20-19. Input for the selection will came from the performance models developed in this task and described in section 2.3, fram the degradation surveys described above, and fram the parametric studies described in section 2.4. The selection will be based on the criteria described in activity E-20-15, and will also be subject to peer review and cument. The rationale for selecting the barrier material (s) before the completion of model development and validation testing is that much more time and effort are required for validation of the performance model than for an informed and defensible selection. That is, a variety of candidates can be examined to a level that determines which ones are conservatively sufficient to meet the performanoe requirenents, and to rank them in tems of performance. That is all that is required at this level to narrow the candidate list to one (or two). Wuch more work is then reguired to camplete the lang term performance model and validate it with testing. This larger effort, which is required for repository performance assessment but not for material selection, can then be focused on the selected alloy(s).

This activity is assigned oi Level $I$. The rationale for this assigment is the same as that given for the previous activity on the selection criteria, because the material selected and the defense of the selection are a fundamental part of the data that will be generated to support the license application. The reasons that the criteria for selection and the selection process itself are split into two activities are (A) to allow the timing sequence of the two activities, (B) to allow a possible change in the calposition of the peer review panel for the two activities, and (C) to docment the selection criteria and the selection process as separate activities. 
In sumary, the three activities for the Metal Barrier selection Process Area are:

Activity No. Rrame ga level

E-20-13

Degradation mode surveys

III

E-20-15

Establishment of criteria for metal

$\mathbf{I}$

barrier selection

E-20-19

Metal barrier selection

I

\subsection{Ketal Barrier Performance Modeling}

These activities are directed toward producing models of material degradation for use in the selection process, and then integrating these degradation models into a metal barrier performance model of the alloy(s) selected, to be validated by laboratory tests and utilized by the repository performance assessment task. Woiel development work will be conchcted at oA Level III. The rodels will be validated at Ievel I and data for parameters central to the model will be collected at Ievel $I$.

\section{Activity E-20-16 Development of models for degradation modes, mechanical} properties and microstructures

Activity E-20-16 'Develogment of models for degradation modes, mechanical properties and microstructures' will serve two primary purposes. one purpose of this activity is to provide support for the selection process. Degradation models, primarily related to the corrosion resistance of the materials but cocasionally concermed with retention of fracture toughness, are based on established electrochemical and metallurgical principles. These models address those modes deemed important to lang term performance as guided by the degradation mode surveys, described in section 2.2. Data irput will include the metallurgical literature (especially that which is related to corrosion), and previous NNhSI experimental work. Closely related to modeling the degradation modes are modeling activities for characterizing the mechanical and microstructural properties of the as-fabricated container and the changes that will ocour ('aging phenomena') as a function of time in the repository. 
For the second purpose of this activity, those models applicable to the selected alloy will be further developed and integrated into a long-term metal barrier performance assessment model to be validated and used by the repository performance assessment task in the advanced design and licensing phases. The rationale is to develop individual degradation mode models for all of the processess which must be considered in the selection activity, then combine those models which are relevant to pcoduce a unified perfonmance assessment model for the container. Thus, the model development activity begins before container material selection and contimues for same time after the selection process.

The models for degradation modes can be broken into 'sub-models'; in same cases this is an advantage because some aspects of the degradation process will be more amenable to modeling than other aspects. One exartple is that the cetection of a sensitized microstnucture in austenitic stainless steels and nickel-base materials is more readily modeled than the erviromental aspects of intergranular attack and intergramular stress corrosion cracking. Another exampie is that ammonia formation (such as by radiolysis of atmospheric gases) is more readily modeled than the metallurgical or mectianical aspects of stress corrosion cracking in cogper and copper-base alloys. In both cases (sensitization or ammonia formation), the process being modeled is the critical step in the degradation mode and can be modeled with greater confidence because the model is confined to either the containar material (sensitization) or to the environment (anmonia formation). This point is discussed further in section 3.3.1.

This activity on model development is assigmed of Level III. The reason for this level assigmment is that the individual models themselves ane not. directly part of the license data base (Level I), nor is the general 'integration' of the models into a single performance model. OA Level III parametric studies (E-20-18) support development of these models (discussed in Section 2.4). The activity on model develogment (and model integration) does not have a major impact on project schedules or on design phases to conduct couparisons of alternatives (criteria for Level II assignment). However, preparation of the integrated performance nokel for use in support of the license application (E-20-20.1), the data to support it (E-20-21.1), and validation of the model (E-20-25) are Level I activities. The validation will be made according to results of key performance parameter studies (E-20-21.1) and with data generated under license application support tests (E-20-23) . Both E-20-21.1 and E-20-23 are of Ievel I activities.

\section{Activity E-20-20 and E-20-20.1 Integration of models for selected material}

The 'Integration of models for selected material' activity (E-20-20 and E-20-20.1) follows the previous development phase and the alloy selection. Those degradation models which apply to the alloy(s) selected must be integrated with the design features and repository envirorment information to produce a long term performance model for the waste package. The reason for this 'integration' activity is that more than one degradation mode can coarr at a time. The model associated with aging effects in the container, including the mechanical and microstrurtural property changes associated with these, and the model associated with los temperature oxidation of the container are applicable from the time the contairer is emplaced in the repository, while many of the other models (especially those associa: ad with aqueous corrosion phencmena) are applicable to rertain time periods or when certain conditions oocur in the repository. 
The envircment around the container will change with time, and waste packages at different locations in the repository will experience different ervirormental conditions. The containers thenselves will be proctuced over a 25-30 year period of time, and will conceivably have some variation in composition and microstructure. All of these factors will determine when a given model is 'in effect' and when it is not.

This activity is split into two parts with different $Q \mathrm{~A}$ levels because much of the work to integrate the models does not support license application directly but is the process of getting the performanoe model working correctly. Thus activity $(\mathrm{E}-20-20)$ is assigned QA Ievel III for the same reasons given for assigning the model development activity (E-20-16) Ievel III. The primary purpose of the integration is to 'allocate' among the several models over what portion of time and over what portion of container population the individual models are applicable. The portion of this activity which is assigned of level I (E-20-20.1) irvolves preparation of the parametric data fram E-20-21.1 and predictions of cantainer performance. This will be used to support the license application and other critical programmatic decisions in other tasks such as container design and fabrication where the metal barrier performanoe is important. The parametric data for this activity comes from $\mathrm{E}-20-21.1$ which is also $\mathrm{g}$ level $\mathrm{I}$.

\section{Activity E-20-21 and E-20-21.1 Performance parameter studies}

'Performance parameter studies' (E-20-21 and E-20-21.1) is an activity to interface with the integration of the individual models (E-20-20 and E-20-20.1), descriked above. This activity involves gathering key parametric imput for the integrated metal barrier model, and guaranteeing that the metal barrier model is consistent with the requirements of the repository performance model. It will also provide any additional parametric data needed to canplete the individual degradation models. The word 'jsey' is used here because the parameters that will be studied are those that are identified as being important because of their strong influence on those degradation modes that are determined to be central in predicting container lifetimes in the time periods of concern. Identification of these key parameters comes after container material selection and after the model develogment work has indicated which parameters have the greatest sensitivity toward the process being modeled (activities E-20-18 and E-20-16). This 'Performanoe parameter studies' activity may include data collection from outside the project and certification of this data acoording to the appropriate quality assurance provisions to allow its use to directly support level I work; this activity may also include laboratory tests. Test's would be performed under this activity if they were not direct performance tests, such as those in activity E-20-23.

This activity is split into two parts with diffecent oA levels because same of the information required for model integration (E-20-20) is of a general nature and does not directly support either the model validation or the license application design, and same of the information does support these Ievel I activities. The first portion of the activity, E-20-21, which is assigned QA Level III, supplies information on all of the physical, chenical, metallungical, and mechanical parameters that have same influenoe on metal performance. It is similar in nature to activity E-20-18 but is focused on the selected material and supports model integration rather than general

development. The second portion of this activity is $\mathrm{E}-20-21.1$ and is assigned QA Level $I$. The rationale for this assignment is that this activity directly supplies input required for completion of the performance madel (E-20-20.1 and E-20-25), QA Level I activities that will be used in the license application 
data base. Activity E-20-21.1 classifies information with regard to its importance and reviews and certifies information needed for $\$ \mathrm{~A}$ Level I activities. Docamentation of these decisions becames a central factor in campleting the modeling work in the Metal Barrier Selection and Testing Task.

\section{Activity $\mathrm{E}-20-25$ Validation of model}

'Validation of model' (E-2(1-25) will validate the integrated metal barrier degradation model by comparison to on Level I test data. As described earlier, the model will be based on accepted electrochemical and metallurgical principles. The raticnale is to verify that the model is phencmenologically correct by comparison to laboratory tests which map a parameter space in corrosion enviromment and time. Demonstration that the model accurately predicts the results of these tests will be used to validate the model for use in the Repository Perfomance Assessment. If suitable natural analogs can be found, they will be used to enhance the validation of the time parameterization. The peer review process may also be used to support model validation.

This activity is assigned of Level $I$, because the results of the validation will be a critical part of the data submitted in support of the license application.

In summary, the activities under the Netal Barrier Performance Nodeling area are:

Activity No. Name ga Lovel

\begin{tabular}{lll}
\hline E-20-16 & $\begin{array}{l}\text { Development of models for degradation } \\
\text { modes, mecinanical properties, and } \\
\text { microstructure }\end{array}$ & III \\
E-20-20 & $\begin{array}{l}\text { Integration of models for selected } \\
\text { material }\end{array}$ & III \\
E-20-20.1 & Ferformance parameter studies & III \\
E-20-21.1 & Performance parameter studies & I \\
E-20-25 & Validation of model & I \\
\hline
\end{tabular}

It should be noted here that detailed model develogment and validation plans cannot be provided until after the material selection process is caipleted. 


\subsection{Netal Barrier Performance Testing}

Laboratory testing of metal barrier performance is required for three reasons. First, in the time leading up to selection of one (or two) alloys, experiments will provide data to the degradation modeling effort and will help guide the selection process. After selection, there will be a need for $O A$ level I imput into the degradation models as they are consolidated into a container performance model. Finally, tests will be needed to provide support for validation of the metal barrier model over a range of repository-relevant parameters.

\section{Activity E-20-17 Experimental technique develogment}

Activity E-20-17 is 'Experimental tecinique development'. Custan laboratory tests are likely to be needed. Standard corrosion test procedures should be adequate for most general material surveys and same of the model development support. However, to precisely conform to the modes of degradation experienced in a repository environment, and to vary the parameters of tests in the same way that the models vary parameters, austan techniques, using recent advances in electrochemical and surface sciences, may be required. To measure the slight degradations experierced in the relatively benign enviroments expected in experiments and tests performed within reascanable time scale, enhanced sensitivity is required in some experimental tectniques. Examples of some technigues that may be employed are discussed in section 3.4.1.

The work in this antivity will be conducted at QA Level III. This is truly experimental work. There is same technological risk imvolved in undertaking this kind of work in that not all of the promised advances in techniques will necessarily give useful results. On the other hand, there are considerable benefits to be gained if mechanistic arguments can be successfully made about how fundamental electrochemical and metallurgical processes qperate, in order to make the unique lang-range characterization and perfonmance predictions required for muclear waste disposal. The bulk of the work undertaken in activity E-20-23 (Iicense application support tests) will likely use standard test procetures and recommended practices developed by professional organizations such as ASTM, NACE, and others. These tests have widespread use and acceptance; however, acoeptance of new kinds of tests by professional organizations is a slow process. A good part of the effort in activities E-20-22 and E-20-23 (both $9 \mathrm{~A}$ Level I activities) will be cancerned with selection of test methods to use in generating the lior $r$ application data. The result of work performed in activity E-20-17 is to ietermine whether same of these advanced tectniques should be included in thos: Level I activities.

\section{Activity E-20-18 Parametric studies of metal degradation and microstructure}

During the development of degradation mode models described in section 2.3 corrosion data will be required that are not available from other sources or are unique to Yuca Mountain repository conditions. These will fall under activity E-20-18 'Parametric degradation studies'. The rationale is to provide the container material selection and model development activities in a timely manner. 
The behavior of the container material depends on several physical, chemical, metallungical, and mochanical parameters; identification of which of these parameters are the central or key ones to predicting the performance under repository conditions is needed to proceed toward generating meaningful data for the license application. This activity begins before selection of container materials for actvanced design work and contimues until the selection process is campleted. After selection of a container material, information gathering and key parameter identification is continued under activity E-20-21.

This activity will be conducted at of Level III. The information that comes out of this activity will not be used directly in the license application, but it will identify those parameters that will be used in generating the $\mathrm{OA}$ Level I work in activities E-20-21.1, E-20-22, and E-20-23.

\section{Activity E-20-22 Develogment of plans for ligense application sumport tests}

After selection of an alloy(s) for advanced design work, a set of os Ievel I tests must be planned in conjunction with the model integration work of Section 2.3 to allow eventual validation of the metal barrier performance model. such tests cannot te conducted until a comprehensive set of test plans has teen prepared, reviewed, and accepted. Preparation of these plans in activity E-20-22 'Development of plans for license application support tests' includes a review and cament process to ensure that the soope, accuracy and precision of the tests will be adequate for perfonmance confirmation.

This planning activity will be developed at $\mathrm{CA}$ Ievel I. Documentation of how decisions were reached with regard to selection cf test methods and selection of key parameters is needed to directly support the license application data (criterion for Ievel I). As indicated in the information flow diagram (Figure 1) and in discussions in the text on related activities, the plans will be periodically revised as important new information becomes available, for example from activity $\mathrm{E}-20-17$ on technique development or from activities E-20-2I and E-20-21.1 on parametric investigations.

\section{Activity 5-20-23 Lioense application support tests}

The most intensive laboratory work in this task is in activity (E-20-23) 'license application support test's'. These tests, as planred in the activity described above, will be used to validate the metal barrier performance model, and will provide data to predict the expected long term metal barrier performance. The rationale behind these tests will be to test the alloy(s) chosen over a range of erviroment and time combinations to provide data for use in specially designed tests for validating the integrated performance model of the metal barrier, as described in activity E-20-25. Severe envinonments will produce measurable degradation in accessible times to validate models of the degradation process. Konitoring the decrease in the degradation kinetics as the enviroment tends toward that in the repository will provide validation of the time parameterization in the models. Iong-time natural analogs, if available, will allow further validation in the time parameter. This activity will be conducted at oA Level I. The reason for this assigmment is that this activity will generate license application design data. 
In summary, the activities in the Hetal Ferformance Testing area are:

\begin{tabular}{llll} 
Activity No. & Name & QA Levei \\
\cline { 3 - 4 } E-20-17 & & Experimental techrique develcqment & III \\
E-20-18 & Parametric degradation studies & III \\
E-20-22 & $\begin{array}{lll}\text { Development of plans for license } \\
\text { application support tests }\end{array}$ & I \\
E-20-23 & License application support tests & I \\
\hline
\end{tabular}

It should be noted here that detailed plans for activities E-20-22 and E-20-23 cannot be developed until after the material selection process is coupleted.

\subsection{Design Properties of Metal Barrier}

This area comprises those properties of the metal barrier (as it is designed to be used in a waste package) that affect material selection and performance. These include the temperature and radiation field die to the radicactive decay, physical and mechanical properties of the metal, design details such as thicimess of the container and the loads that it will experience, and nicrostnuctural characteristics such as grain size and internal precipitates both in the weld metal and the base metal. There are two activities in this area.

\section{Activity E-20-14 coordination with package desion}

The first activity in this area is 'Coordination with package design' $(E-20-14)$. The rationale behind this activity is to ensure contimued information exchange with the package design task. Examples of the kinds of information exchange are given in section 3.5.1. This co-ordiration is required to assure that the metal barrier selection and package design do not progress independently and end up with incampatible requirements.

This activity will be conducted at GA Level III as there is no license apglication design data being generated in the activity. This activity will continue throughout the active period of this SIP; the activity is not directly linked to any particular inportant scheduled milestone. However, this activity does serve to transmit information between the two tasks. Information from analyses being performed in other activities (e.g. E-20-18, E-20-21, and $\mathrm{E}-20-21.1$ ) is used to determine 'Key' parameters (especially metallurgical parameters). Information flows back fram this activity to identify which of the mechanical and microstructural properties are central to making performance predictions (activity E-20-24). 
This activity is concemed with characterization and docamentation of the il portant mechanical and nicrostructural properties of the selected container naterial in the as-fabricated and as-emplaced condition. Many of the activities cancerned with survey of degradation modes, identification of key perfonance-related parameters, molel deveiognent and integration, and testing to produce license application data and validation of the performance model depend on an acanrate characterization of these key properties. This activity is closely linked with the Design, Fabrication, and Prototype Testing Task because the container fabrication process and the welding or other closure process have a significant influenoe on the mechanical and nicrostructural properties. Bxaples of mechanical and vicrostructural properties are given in section 3.5.2. The partiallar properties that will be docamented in this activity are those that are deend important from the model developnent and integration activities (E-20-16 and E-20-20) and the parametric stadies (E-20-18, E-20-21 and E-20-21.1). Additionally, from the point of view of fabricating, closing, and inspecting the container, there are certain desirable mechanical and wicrostructural properties, and these considerations ust also weigh in the final naterial specifications.

Infonation fram this activity will ultinstely be used, in part, for establishing accetance criteria for the waste package container. This information is Frovided to the Design Task and ultimately to those areas of the Niwi Project respansible for the waste package manfacturing and handling facilities. Nearly all testing techniques for mechanical or microstructural properties are destructive. Therefore, a mjor contribution from this activity vill be a technical basis for establishing a sampling progran to assure that the finished container nets the specifications. Pussible approaches to achieve this end are core fully explained in $\mathrm{IN} 1.4 .1$ of the SCP.

This activity will be conduted at os Ievel I. The characterization and doamentation of these properties serve as a basis for much of the modeling and testing took frow wich long-tem perfor ance behavior predictions are derived. Characterization of the starting conditions is a coucial point in establishing the validity of the predictions, and this neets the criterion for Level I (data for license application).

In sw mary, the activities under the graping of Design Properties of the Hetal Barrier are:

Activity No. Name

E-20-14

$E-20-24$ coordination with package design

Determination of nochanical and microstructural properties of selected metal barrier material
QA Ienel

III

$\mathbf{I}$ 


\subsection{Introduction}

The thirteen activities defined in sections $2.1-2.4$ are described in the following sections. For those activities in which previous NWWSI work has been performed, that work is described. An outline of the work planned under this Irvestigations Plan is included. Detailed test, model, and analysis plans which will ultimately be required by this Investigation are listed in Section 5.0.

\subsection{Netal Barrier Selection. Process}

\subsubsection{Degradaticn mode surveys $(\mathrm{E}-20-13)$}

This activity is an analysis of all the degradation modes that are believed to pose a potential performance threat to one or more of the candidate metals for the container. These surveys will be a set of papers sumarizing available information addressing whether any particular mode of degradation can be active under Yuoca Mountain conditions, under what conditions it would be active, and what measures could be taken to avoid degradation. The surveys will become a baseline of information used to evaluate which degradation modes must be pursued in advanced tests and which can be eliminated from further consideration because they will not be active under postulated repository conditions. The surveys will also supart the selection process, where they will provide input into a gA level I assessuent of the degradation modes. That assessment will then be used to narrow the field of candidate metals to one or two. It is expected that sone candidates will have more potential degradation threats than others. Selection criteria may favor those candidates that have few or no active degradation modes. A final application of the surveys will be as input to the Package Design Task to assist in evaluating design issues which could reduce or enhance the activity of degradation modes.

The candidate metals can be divided into two distinct alloy families, austenitic (iran-base and nickel-base) and copper-base. These families respand quite difisrently to the same envirament. Because of this natural grouping, the assessments will be combinations of degradation mode and alloy family. While the fundamental mechanisms for corrosion resistance are similar within a family of alloys, individual members can exhibit substantial differences in behavior in certain enviranvents. The cammon modes of environmental degradation can also be grouped into similar categories. Not all degradation categories apply to both alloy families, because some types of corrosion are not active with one of the families. Thirteen cominations of degradation mode and metal family have been identified that are at least canceivable under repasitory conditions. There is also a category of 'other' to allow continued survey of possible modes that appear remote now but that future imvestigations in this and other project tasks may reveal to be more illportant. Identified in this 'other' category are (1) additional mechanical degradation modes (e.g. low temperature creep) cocaurring at slow rates over lang periods of time at the modestly elevated temperature in the repository and (2) the possibility of greatly enhanced corrosion degradation modes ocurring because of substantial modification of the chemical enviranment by micro-organisens either native to the repaitory site or introchuced curing the construction and cperational periods. 
General oorrssion and oxidation - Copper-base alloys.

Iocalized corrosion - Copper-base alloys.

stress Corrosion cracking - Oopper-base alloys.

Hydrogen Effects - Cogper-base alloys.

Phase Stability and Ageing - copper-base alloys.

Other Degradation (Creep) - Copper-base alloys.

- - - -

General Corrosion and oxidation - Austenitic alloys.

Iocalized corrosion - Austenitic alloys.

Transgranular Stress Corrosion Cracking - Austenitic alloys.

Intergranular Stress corrosion cracking - Austenitic alloys.

Hydrogen Effects - Austenitic alloys.

Fhase Transformation and Ageing - Austenitic alloys.

other Degradation -Austenitic alloys.

\subsubsection{Establishment of criterja for metal barrier selection_(E-20-15)}

The objective of this activity is the development of a methodology to select the container material fran the list of candidate materials. A peer review grow will be formed as provided for under the NNMP - QAPP (033-Min-P 2.2) to review this methodology and its use in arriving at the final material choice.

The following list is a peliminary list of the oriteria for selecting a container material for the license application design and will serve as input to this activity:

1. Will the material meet the performance allocated to the container in achieving the containment objectives (substantially complete containment under anticipated processes and events oocurring in the repository)?
a. Resistance to oridation.
b. Resistance to general aquecus corrosicn.
c. Resistance to envirarmentally acoelerated cracking (stress corrosion cracking and hydrogen embrittlement).
d. Resistance to pitting, crevice, or other localized attack.
e. Demonstration of adequate mechanical properties.
f. Resistance to mechanical embrittlement.

2. Can the performance of the material under repository canditions be adequately predicted?
a. Predictability of physical and chemical properties of as-einplaced container.
b. Existence of models to explain and predict degradation phercmena, or ability to develop such models.
c. Existence of models to extrapolate laboratory data relating to degradation phencmena to repository time scales and conditions, or ability to develop sach models.


3. Will the container material interact favorably with other components?
a. Interactions with waste form.
b. Interactions with borehole liner.
c. Interactions with the package ervirament.

4. Can a container be made of this material?
a. Fabricability of container body.
b. Weldability of container ("closeability" if a nonwelded closure).
c. "Inspectability" of closure.

5. Are the container material and process for fabricating it practicable?
a. Availability of container material.
b. As-fabricated container costs.
c. Quality control requirements (and costs).
d. Repository handling costs.

6. How can confidence in the selection be gained?
a. Previous engineering applications of the material.
b. Available data base on the material.
c. Favorable (or unfavorable) experiences with the material.

Weighting factors for each of the preceding criteria (and any others chosen) will noed to be established. It is expected that the previcusly listed criteria in 1, 2 and 4 will have the heaviest weighting, but all of the criteria have same importance. One approach is to assign a maximm nmber of points to each item in the criteria list and a minimm number for each item that the material must pass. As a rather extreme expule, it does no good to have a highly corrosion resistant material that cannot be fabricated and closed.

There appropriate and available, examples of methods that have sucoessfully been used to predict longer term behavior of materials fram short-time labotatory or field tests will be used. Examples may derive from atmospheric corrosion testing, marine corrosion testing, underground testing, chemical process industry testing, or nuclear and fossil fuel power plant testing. These examples will provide information for some of the itens listed in 1, 2 and 6. 
Develogment of the selectian criteria, weightings, and organization of the peer neview group are the itens to be completed in this activity. The Nevada Muclear haste Storage Investigations (NWSI) Project will use its own staff and consultants to develop the selection criteria and weighting factors. The selection criteria and weightings will then be reviewed by the peer review panel as per the quality Assurance Program Plan. Following revision, if necessary, the criteria will be used to assess the candidate materials and select a material or materials in activity E-20-19. The peer review panel will consist of approximately seven individuals with backgrounds in different areas of metallurgy and materials science and with different work experienoes to achieve a balance of viewpoints and perceptions.

\subsubsection{Wetal barrier selection (E-20-19)}

This activity is the actual metal barrier selection step. The selection process will consist of applying the selection criteria to the list of candidate materials. As part of the process an assessment of degradation modes will be made for each matertal based on the survey papers from activity E-20-13. NMSI Project personnel and consultants will perform the selection. Inqut will be the selection criteria and weighting factors from the previous activity, the degradation mode surveys from the first activity, consultant reports, MNRSI parameter studies, and existing literature information. There will be two components to the decision. First, each candidate will be examined to assure that its performance meets the minimm requirements, allowing a conservative margin for uncertainties. Second, it is proposed that a 'quantitative figure of merit' technique be used, in which each candidate alloy is judged on the established criteria. The quantitative soores, multiplied by the established weighting factors, are summed to provide the ranking total for the alloy. The selection process will be documented in a report on alloy selection. A peer review panel will be convened to review the report. It is expected that the same panel used for activity E-20-15 will be used for this review, but scme additions might be made to address critical decision points. The selection, after review, revision if needed, and approval by the review group, shall be used to guide subsequent performance confirmation tests and degradation model develogment. The selected metal barrier material(s) and its physical, mochanical, and microstructural properties will also be used by the waste package design task as input into the advanced design work. 


\subsection{Netal Barrier Performance Modeling}

\subsubsection{Develogment of models for deqradation modes, mechanical properties, and miconstucture (E-20-16)}

The analyses performed under this activity are directed towand produxing a set of models for any degradation modes to which the container may be susceptible. The set of models will oover all degradation modes considered to be important for each candidate material in the repository environnental and thermal setting. The models will be preliminary in nature because of the large effort required to make them exhaustive, and because of the limited application required of these models before the selection step. Those models relevant to the selected alloy(s) will be further developed after selectian, as described in activity E-20-20. This activity will also develop models to predict the mechanical properties and microstructure of the container material in the repository erviconment.

Prediction of the lang-term performance of the metal barrier under: repository conditions requires that all significant degradation mechanisms be identified and the probability of their occurrence be quantified. For all degradation modes that might be significant, a physical-chenical model must be developed that will allow extrapolation of data gathered in the laboratory to the times and conditions relevant to the repository. In many cases, the analysis to determine whether the degradation mode might oocur requires the same model that will allow prediction of long-term behavior. Thus, in this activity analyses are included that both assess the relevance of particular degradation processes and develop models to describe their action under repository conditions. The tools that are developed under this activity will be used in the Performance Assessment Task to predict the condition of the containers as a function of time for both anticipated processes and events and for other, low probability cases for which source term data are requested by that Task.

The modeling activities discussed in this activity and the laboratory experiments discussed in E-20-18 are closely related. They are both described in fairly basic terms in Chapter 8 of the SCP (Information Need 1.4.3) with much greater detail to be provided in the laboratory test plan to be written for the activities. The results of this activity will be used in the selection of the alloy(s) for advanced work (activity E-20-19), and those portions of these models that apply to the alloy(s) selected will be used in activity $\mathrm{E}-20-20$.

A fundamental element that transcends all the modeling of degradation modes that have some chenical features is a model for the corrosion potential. Various envirormental parameters in the aqueous phase (e.g. pH, dissolved oxygen and other gasses, cation speciation, anion speciation, radiolytically proculuced species as well as temperature) influence the corrosion potential. Metallurgical parameters (e.g. alloy camposition and phases - including the effects of strain and prior fabrication history on these) also influence the corrosion potential. Wile more difficult to measure experimentally, the concept of corrosion potential also exists under "dry" oxidation conditions. The potential under dry conditions might be approximated by modeling the potential under conditions of a thin electrolyte layer as a function of thickness, and then letting the thickness approach zero. Initiation and propagation of non-uniform corrosion modes are governed by "critical potentials", so that models for these modes are based on the values of the 
critical potentials relative to the corrosion potentials. The values of the critical and corrosion potentials will change with time as errirormental and metallungical conditions in the repository and in the container material change. Nany of the details depend on the material that is selected for the advanced designs.

Models for predicting critically susceptible microstnuctures for the onset of non-uniforn corrosion modes (e.g. sensitization in stainless steels and nickel-base materials) are derived from considerations of the metallungical reaction kinetics. These follow fram nucleation-and-growth models based on diffusion of the critical companent (diffusion of chramium to react with carton). Particularly at the relatively low temperatures of interest in the repository, models must consider both high-diffusivity paths (grain boundaries, dislocations) and low-diffusivity paths (atom movements in the crystal matrix). Also, the reaction kinetics to form the carbiae can become rate controlling at low temperatures. Wodels for sigma phase formation (a brittle phase) are based on micleation and growth kinetics and will be developed by a similar approach. Scme metallurgical reactions that are of interest (because the transformation products are brittle and are usually more prone to stress corrosicn and/or hydrogen embrittlenent) are diffusionless (e.g., martensitic reactions in stainless steels and possibly in aluminum bronze), and the modeling approach is therefore different. Martensitic neactions are usually considerad in the context of critical temperatures to begin the transformation and to complete the transfonmation. High strains greatly increase the critical temperatures, so that they can ooincide with the repository temperatures for the more susceptible materials (304L). Models for these are built upon the effect of temperature, strain, and alloy composition with evidence for the formation being resolution by optical microscopy.

The extent to which the modeling activities will be carried art depends on the material selected for advanced designs and the results of degradation mode assessments for the materials and different degradation modes being considered.

\subsubsection{Integration of models for selected material (E-20-20 and E-20-20.1)}

The analyses of this activity follow those of the preceding one (E-20-16) and the metal barrier selection step (E-20-19). This activity involves taking those degradation mode models that are relevant to the selected alloy, completing them, and integrating them with required input fram activity E-20-21 and E-20-21.1 conoerning the material and repository conditions to provide performance predictions for the metal barrier. This activity will interface with the Performance Assessment Task to produce container performance models consistent with the needs of that Task.

The work of this activity is closely related to the information gathering and laboratory testing activities of E-20-21, E-20-21.1 and E-20-23. They are described in general terms in Chapter 8 of the SCP (Information Need 1.4.2) and will be detailed in the indivicual test and analysis plans to be written for the material (s) selected for the actvanced designs. Particularly in the case of localized corrosion and stress corrosion cracking, there is a considerable need to select detailed test methods as well as materials, and this selection is best left until after the final material is selected. 


\subsubsection{Performance parameter studies (E-20-21 and E-20-21.1)}

The gA Level III portion of this activity (E-20-21) consists of information collection and tests to support the development of degradation models but which do not support the validation and license application. This activity serves a role after the selection step similar in nature to the role of activity E-20-18 before selection. This activity continues those experiments from E-20-18 which apply to the selected alloy to assist model development. The experiments can be divided into eight categories of degradation, and can be fur ther divided naturally into the two families of candidate alloys (austenitic and copper-base). The eight categories ane:

1. Metallurgical aging and phase transformations.

2. Low temperature oxidation

3. General aqueous corrosion.

4. Intergranular attack and intergramular stress corrosion cracking.

5. Hydrogen entry and embrittlenent.

6. Pitting, crevice, and other localized attack.

7. Transgranular stress corrosion cracking.

8. Other potential degradation modes

The $Q A$ Ievel I portion of this activity (E-2O-21.1) cansists of information collection and tests to support the completion and integration of degradation models including any data which supports the validation (E-20-25) or the license application design. Details of this activity will not be available until the preliminary models are complete (E-20-16), the alloy(s) for actuanced design work is chosen (E-20-19), and model integration (E-20-20) is ready to conmence. Until that time, the parametric information needs for this task will not be known. When appropriate, analysis and or test plans will be prepared and reviewed to assure that the parametric input into the metal barrier performance model is adequate and accurate. This activity is a of Level I analog of activity E-20-18 and will gather or generate data on critical issues such as chramium diffusion, phase stability, and chloride ion effects (austenitic materials) and such as rates and concentrations of ritric acid or ammonia formation (copper-base materials). The data will be used in the develogment and integration of the performance model $(E-20-20.1)$ but are not distinct validation tests $(\mathrm{E}-20-25)$.

\subsubsection{Validation of model (E-20-25)}

This activity will conduct oA Ievel I metal barrier material tests and compare the results with the predictions of the degradation model. The purpose is validation of the model for long term waste package performance predictions. Substantial variance of the model fram the test results must be investigated and explained. A peer review process will monitor the results and review the validation. Irqut into this activity wlll be the long term material performance model from E-20-20.1 and the test results fram E-20-23. 


\subsection{Netal Barrier performance Testing}

\subsubsection{Experimental technique develogment (E-20-17)}

This activity involves the develogment of custan laboratory techniques for degradation testing and exrmination of metal barrier candidates. It involves both analyses of requirements and existing techniques and laboratory testing to develop techniques. One portion of this activity will be an ongoing review of the experimental requirements for metal barrier testing. As the investigation progresses, there may be an evolution of test aquirements, since they are dependent upan the results of activities E-20-13, E-20-19, and E-20-16. As these experimental requirenents are identified, an assessment of existing techniques will be made to determine whether the need is already filled. Bstablished techniques that are required but not already avaliable to the INWSI program will be cotained, either by installing and developing expertise at IINL or by contract to other laboratories with established capabilities. It is possible that needs will be identified that are not met by established techniques. In this case, an effort will be made to devesop the required capability either at INNL or at a contractor facility. The work under this activity will be done at $O A$ level III. However, any tectmiques developed here that will be used for activities $\mathrm{E}-20-21.1$ or $\mathrm{E}-20-23$ will have oA Level I procedures written for them. include:

Examples of experimental requirements that may lead to developmental work

1) use of microelectrodes to measure and monitor electrochemical potentials in small areas. A great deal of tectmical literature is concerned with measurenent of electrode kinetics as a function of statically or dynamically applied electrochemical potentials. On this basis, potential regions are established. These regions are bounded by so-called 'critical potentials' that govern where partiallar kinds of corrosion can cocur. In conventional electrochemical technigues, potentials are measured on areas with a linear dimension of approximately $1 \mathrm{~mm}$, while advanced tectniques allow potential measurements on area with 1 inear dimensions of 10 micrometers, and considerably less in the most advanoed techniques (about 30 nancmeters). This advancement permits an experimenter to monitor the potential distribution that would oocur around a freshly initiated crack, crevice, pit, or other surface feature on a corroding metal surface. corventional electochemical tectuniques will canplement the microelectrode work.

2) vise of advanced microanalytical tectniques to measure and monitor the conoumitant ervironmental chemical vancentration gradients along with the electrochemical potential gradients existing in a crack, crevice, pit or other surface feature on a corroding metal surface. Such techniques involve selective ion probes or intense light sources. 
3) use of advanced microscopic techniques to investigate changes occurring in the metal or alloy. These tectiniques include advancements in scaming and transmission electrai microscogy to examine and analyze very small precipitates, transformation products, or other microstructural features of interest. With the latest "state of the art" microscopes, resolution to 10 Angstrams (and lower) is possible. Resolution of these small particles is important in establishing credibility of metallurgical models (e.g. sensitization in stainless steels; martensitic transformations in stainless steel and possibly aluminum bronze) proposed for predicting changes in the container material with time.

4) use of advanced surface and analytical techniques to investigate the chemical and structural composition of protective films and layers on corroding metal surfaces. Fran this information, the kinetics of film formation and re-formation when broken can be determined. Of possible interest are advancements in scaming tumneling electron miccoscopy to examine in situ surfaces exposed to aqueous envirorments, and spectroscopic ellipscometric techniques to investigate in situ the structure and growth kinetics of passive films. More conventional in vacuo techniques, e.g. Auger electron spectroscopy and ESCA techniques, will be used to supplement the in situ techniques, as needed.

The intent in developing the above techniques is to allow examination of grain boundaries, arrays of dislocations, sub-critical size precipitates, local anodes and cathodes, and other fundamental factors in elucidating the mechanisms for corrosion and other degradation modes. These advanoed techniques are to be used in conjunction with more established and ocnventianal corrasion test methods (as discussed in the next section)

\subsection{2 parametric studies of metal degradation and microstnucture (B-20-18)}

The work in this activity will be gA level III experiments to provide specific corrosion data needed throughout the model develoquent phase, and to act as irput to the selection process. Those studies to be used in the selection process are needed in the near term. Some of these are curnently planned and should begin soon. Examples of these near term studies include:

Identification of the sensitization rate-detemining step in austenitic stainless steel at low temperatures (Cr diffusion within grains, Cr diffusion along dislocations, rate of carbide formation, etc.) and develop a means to show this microscopically.

Determine the lowest critical chloride ion concentration (lowest critical potential) that will cause 1) pitting, 2) crevice, 3) transgranular soc in the three austenitic alloys and develop means to demonstrate this.

Verification that a high radiation field will not cause a high oxidation or general corrosion rate, or onset of soc by ammonia formation in copper-base materials. 
A substantial amount of previous work has been dane by the NNWSI Project on experiments to examine these issues in ielevant environments. A variety of experiments were conducted at Lawrence Livermore National Laboratory from 1982 to 1986. Additional experimental work was conducted at several contractor sites (Pacific Northwest Iaboratory, hestinghouse Hanford $\infty .$, , Ohio State University, San Diego State University, University of Mimesota, and the University of Florida). These are described in a general way in the site Characterization Plan (Section 7.4.2) and same of the reports from these experimental activities are cited in section 7.0 of this SIP. Several additional reports are in preparation. These reports vill serve as input to the 'Degradaticn mode surveys' of activity E-20-13.

The candidate materials in the NWSI Project are regarded as corrosion resistant materials, as opposed to corrosion allowance materials. This means that the oxddation and qeneral corrosion rates for the candidate materials in all the anticlpated enviranments (and in many of the credible, although unanticipated, enviroments) curing the contaiment and isolation periods are sufficiently low that perforation of the container wall in the time periods of concern by these mechinisms is very improbable. However, these modes will cocur continuasily from the time of emplacement, and they are of interest in establishing the background conditions (including the characterization of protective films and their change with time) for the metal surface.

The more serious cancerns for container failure curing the time periods of interest are the other corrosion modes listed above as well as metallurgical aging and transformation reactions leading to stnuctures that are brittie or more subject to localized corrosion and stress corrosion modes. Warty of the advanced techniques listed in the previous section are planned to be used for the purpose of investigating under what conditions these corrosion modes are initiated and propagated. The bulk of this activity is analysis of the rates of initiation and propagation, as they apply to the enviromental conditions (including temperature and radiation fields) and the population of containers (including their fabrication history and mechanical stress distribution). These conditions will not be uniformly distributed on the surface of a given container and will vary among the population of emplaced containers in the repository. Iocalized corrosion, stress corrosion, and hydzogen embrittlement have important statistical components, related to the distribution of environmental, metallurgical, and strain canditions from point to point, and the manifestation of these is a distribution in the rate of attack by these modes. 
As discussed under activity E-20-16 'Development of models for degradation modes, mechanical properties, and microstructure', the fundamental "tie line" between the different degradation modes is the relationship between critical potentials for the initiation and propagation steps of the different modes of localized and stress corrosion and the electrochemical corrosion potential. Measurement of the corrosion potential and the various critical potentials is the key link between the modeling and performance activities. This means that, for example, a series of pre-cracked stress corrosion cracking tests will be conducted on a suitable fracture mechanics-type of specimen at different applied potentials in a given set of otherwise constant environment conditions. The crack propagation rate will then be measured as a function of time and applied potential. The critical potential for initiation of measurable crack growth is then determined. Other pieces of information, such as the crack propagation rate, the crystallographic path, contimuity or discontimuity of the propagation, and tendency toward crack brarching, will be used eventually to estimate the time-to-failure of a container. Several metallurgical parameters can be introduced into the test series to indicate the effects of key microstructural parameters such as degree of sensitization (stainless steels) or aluminum segregation (aluminum bronze) on the crack propagation rate and critical potential. The effect of mechanical factors such as stress intensity and size of the plastic zone on crack propagation and critical potential can also be obtained from the same series of experiments. Thus, a single set of experiments (with parameters well chosen and with a high degree of sensitivity to crack growth measurements) can yield an impressive amount of information that can be used to predict failure rates. Also, all three of the basic factors (susceptible microstructure, aggressive enviroment, critical stress) needed in determining stress corrosion susceptibility will be present in the test series.

\subsubsection{Develgument of plans for license apolication sugport tests (E-20-22)}

The purpose of this activity is to produce the test plans for the long term tests of metal barrier performance. After the selection process has chosen one (or two) metal alloys for advanced work, tests will be required to determine the behavior of that metal in a variety of erviraments. The plans for those tests must be sufficient to provide the data needed to model the performance of the metal barrier. These plans will be developed by NWSI perscomel and contractors as a gA level I task.

Detailed preparation of these plans will not be possible until activities $\mathrm{E}-20-13$ and E-20-19, that serve as input to the plans, are camplete, and results are available fram the early portions of E-20-17 and E-20-18. Scme examples of tests that might follow are sensitive weight loss coupon tests, crevice tests (with controlled crevice gap sizes), and constant load stress corrosion tests (on both smooth and pre-aracked specimens). In several cases, these will be designed as "mull tests", where the prediction is that no measurable effect should ocour. The credibility of the null tests is established on the sensitivity of the measurement and the time over which the tests are conducted. It is impassible to demonstrate lang-term predictions on mull tests alone, but mul tests conducted in acoordance with a credible model that predicts no effect should add substance to the demonstration. 


\subsubsection{License application sumport tests (E-20-23)}

This activity is the $Q$ level I performance testing of the selected metal barrier. After the candidate alloys have been found to meet minimum performance requirements and have been ranked against one another, one (or two) alloy (s) will became the selected metal barrier material(s) for advanoed design work (see activity E-20-19). The job of this irvestigation icyond that point is to concentrate on this selected alloy to produce a validated model for its long term performance in the yuca Mourtain erviromment and to produce the data required by the model to predict that performance. Data required for the model to expport the license application is the product of this activity. The previous activity (E-20-22) describes the preparation of the plans for these tests. Details of the tests will not be available until completion of the plans. Note that data used specifically for the model validation (activity $\mathrm{E}-20-25)$ will be produced in activity $\mathrm{E}-20-25$.

Until campletion of the metal barrier selection process, the description and goals of these tests camot be finalized. It is expected that the tests will include both anticipated repository service envircrmenc and material conditions whith should yield null results for material degradation, and more aggressive conditions which should yield a result predictable by the performanoe model. Material conditions include simulated or actural weld microstructures, as well as representative base metal conditicns.

Examples of types of tests which might be selected are:

weight loss coupon tests (general aqueous corrosion and oxidation, also indicates pitting and other localized attack), crevice cell corrosion tests, slow strain rate tests (stress corrosion cracking), constant load stress corrosion tests, constant deformation stress corrosion tests (C-rings, U-bends, bent beam), fracture mechanics tests (stress cormosion and hydrogen embrittlement), electrochemical polarization tests (general and localized corrosion), various stress corrosion tests at oonstant applied potentials, localized and stress corrosion tests in irradiated enviruments, "sccatch" pchential or other tests to indicate the mechanical and electrochemical breakdown of passive films, straining electrode tests (film rupture and repassivation kinetics in analysis of localized and stress corrosion analyses), hydrogen permeation tests, double cantilever bean tests (hydrogen embrittlement and stress corrosion cracking susceptibility), corrosion tests using AC impedance techniques (general corrosion for determining passive film characteristics), multiple sample techniques using stochastic analysis (probability for localized corrosion), scanning electrode imaging (localized pH and other chemical changes in sequestered regions), analysis of electrochemical noise (pitting frequency), in situ Raman spectroscopy (speciation in passive films particularly on copper-base alloys to show selective leaching). low-angle $X$-ray (oxidation films), stress wave enission (discontimuity of stress corrosion crack propagation), ion chromatography (determination of anions and cations in solution), and band gap measurements (identify film species).

Other possible techniques of an advanced nature are discussed under activity $\mathrm{E}-20-17$. 


\subsection{Desicm Properties of Netal Barrier}

\subsubsection{Coondination with package desion (E-20-14)}

This activity is the interaction and information interface between the metal barrier task and the package design task. The purpose of this activity is to pnovide an ongoing analysis of the interaction between the decisions and information gained by the Metal Barrier Selection and Testing task and the Waste Package Design task. There are many potential impacts, both beneficial and actverse, that these two tasks could have on each other. The Metal Barrier Selection and Testing Task interfaces with several other tasks (as indicated in Figure 1); these interfaces are handled by communication between the affected Task Ieaders. However, the interface with the Design, Fabrication, and Prototype Testing Task is regarded as the most important one, and therefore warrants a special activity.

Some examples of these Metal Barrier - Design interactions include the criteria of "fabricability" and "weldability" for the container material selection. In mamy cases, small changes in the alloy camposition (particularly in micro-constituents) play an important role in determining the weldability $\mathrm{O}^{2}$ different candidate materials and may influence (and improve) the corrosion performance of the material. The metallungical and microstructural features of the weld are important parameters in selecting a technique for non-destructive evaluation of the weld. The choice of the methods used for fabricating and for welding the metal container (or other closure method) are important

considerations in evaluating the performance of the container material, because of the close relationship between composition (and its variations in the welded region and heat affected zone), microstructure, residual stress, and the susceptibility to the forms of corrosion (localized corrosion, stress cornosion cracking) that are important in limiting the container integrity. Furthermore, the processes for fabricating and closing the container are viewed as having an important influence on metallurgical reactions (such as phase transformations and precipitation of corbides and other phases) in the metallurgically metastable candidate materials. Non-welded clowure methods also have important implications in the corrosion performance of the closure region.

Handling and emplacement operations in the repository also need to be considered in establishing the long-term container performance, since these goerations may impart scme degnee of surface defects and contamination on the container. Some aspects of the repository design nork (not a respansibility of IINL, but closely manitored by the Waste Package Design Task) also influence the performance of the container. These include the enplacement gecmetry, areal power loading of containers, and the borehole liner configuration. Also, the choice of cements, grouts, or other materials to support the borehole liner need to be reviewed as to their effect (favorable or unfavorable) $m$ the container material performanoe.

It is, therefore, the function of this activity to review all of the issues and activities of the two tasks, docment their interaction, and insure communication of that interaction. Information will be gathered fram the design task under this activity, sorted by QA Ievel and application, and passed on to other activities of this plan. No specific tests or analyses are planned for this activity. 


\subsubsection{Deternination of sechamical and microstructural properties of metal $(\mathrm{B}-20-24)$}

This activity provides inforeation about the mechanical and microstructural candition of the container material at the time of elplacement. After the container aterial and the fabrication and closure processes have been selected this activity will detenine those waterial properties that affect the perfonance of the container, and in many cases set liwitations on the acoptable range of those properties. This infanation will be used as input to the perfonance wodel and will also be used by the Package Design Task. The results of this activity ay also fom a set of specifications ani tolerances for material production, fabrication, and closure.

The principal mochanical properties of interest are the following:

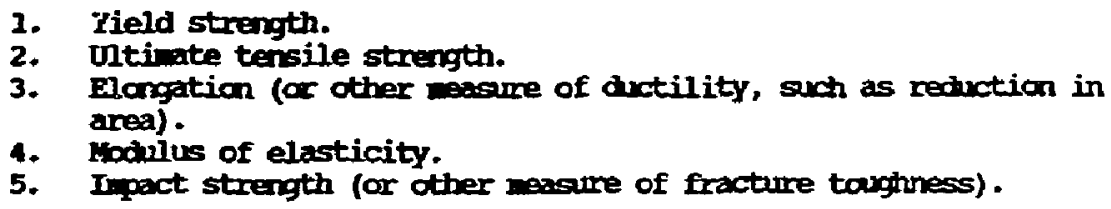

Krodleige of the effect of ntal fabrication processing and interrelationships between mechanical properties and nicrostnuctural properties is also required. This includes the effect of such factors as phase distribution, grain size, inclusion content, and previous plastic deforwation. The effect of the strain rate on the mechanical properties is also needed. Thile individual nechanical properties are listed above, the entire stress-strain relationship serits attention in arder to enable ane to evaluate the taughness of the waterial wen subjected either to low strain rate or to bigh strain rate processes orring handling or that can later develop in the cantainent period.

Because the ricrostructure is intimately related to fabrication process variables and, in scoe cases, to relatively sall copositional variations, this dependence will be doamented. The nicrostructures of the fusian zane and heat-affected zones around the weld wst also be characterized; characterization of theee depends strongly on the velding process variables, and in sone velding processes, on the coposition of the filler materials. The microstructural features of ilportance include the following:

2. Primary phases present and their distribution.

2. Securiary phases and evidience of precipitation reactions.

3. Segregation effects.

4. Grain size and distributian of grain size.

5. Dviderce of peferred crientation.

6. Identification and distribution of nanetallic inclusions.

The tive at elevated te perature (aming the ountainer fabrication and closure process) is influential in deternining the above features. 


\section{0 spolication of pesults}

The activities of this imestigation directly address Issue 1.4 of the Site Characterization Plan. The primary applications of the results will be: 1) to select a material(s) for actuanod design work for use by the Waste Puckage Design Task, and 2) to provide a validated model (and data for use by the model) of that material's lang-term behavior in the repository envirament to the Perfomance Assessment Task. The secondary application of the results is to indicate what changes (if any) the presence of the metailic container produces on the package and repository ervirament. These changes would be inoorporated into the EQ3/6 geochemical code and its subsequent use in establishing performance of other waste package couponents. The infomation, test results, and models obtained in this investigation will also be applied in several other ways:

1. To provide, along with a considerable amount of information supplied by the Design, Fabrication, and Prototype Testing Task, a description of the "as-emplaced" container for use in predicting repository performance.

2. To establish meaningful laboratory test conditions for activities discussed under the grouping 'Hetal Barrier Ferformance Testing'. Results from these tests input into the models for she different degradation modes. These test conditions specify the enviranmental, metal lurgical and strain conditions that govern the susceptibility to certain forms of localized corrosion, stress corrosion cracking, and mydrogen embrittlement (those forms of corrosion are espected to be wost important in liviting the container lifetime in the time periods of concem in demotrating contaiment and controlled release). For scme of the candidate alloys, projections of microstructures that may develop over the lang-tern contairment period are important because of either potential enbrittlement problens or greater susceptibility to different corrosion nodes. Analysis of the expected as-fabricated, as-welded (or otherwise assembled), as-enplaced structure serves as the basis for begining these projections.

3. To form part of the basis for materials selection for final waste package designs, and to complete that selection. The selection process is discussed in activities E-20-15 and E-20-19. As discussed in section 3.2.2, it is anticipated that the perfomance under expected repository conditions, the predictability of the performance, and the fabricability of the material will be the paramount criteria, but considerations of mechanical and physical properties plus other practical considerations way be expected to play an important role in the selection process. An important part of the fabricability and weldability issues relates to whether or not unfavorable mechanical-microstructural features are produced in an otherwise resistant material.

4. To form a basis for establishing ary additional specifications on the composition and mechanical properties of the candidate materials beyand the nomal industry specifications. 
5. To provide guidance in selecting the industrial processes for forming, joining, and handling the container. These results will further serve as input to information needs under Issues 2.1 (Options for retrievability), 2.6 (Preclosure design criteria), 4.3 (Waste package production technology), and 4.5 (Waste package costs).

6. To cuplete certain elements of the waste package design which are materials-dependent. Most waste package design features, at the conceptual level, are not sensitive to wich material is eventually selected. At the advanoed design stage, detail on the selected material and processes for producing and handling the container is needed. These results are ingut into Information Need 1.10.2.

7. To camplete cansiderations in several repository design-related options. These include a decision on whether the containers are euplaced horizontally or vertically in the boreholes, and the use and configuration of borebole liner materials (currently it is suggested to use comparable materials for the container and borehole liner to eliminate any galvanic corrosion effects). Also, the emplacement and cperational activities in the repository may be partly influenced by the container material selected, to insure that prijections on its performance are not compromised.

8. To provide to the Waste Package Ervincrment Task a description of the corrosion products that are expected to form in the near-package ervirarment. These species may influence the performance of other waste package coupanents and are of interest in assessing the modification to the natural enviroment caused by degradation of the waste package container. 
The following test and analysis plans will describe in detail the activities forming this investigation:

Netal barrier selection neview plan

Metal barrier test plan (for selected material)

Metal barrier degradation model development and integration plan (for selected materiai)

Ketal barrier performance model validation plan

The test plan and plan for model develogment and integration depend very much on which material is selected for advanced design work. Plans for testing and modeling are centered around the appropriate and applicable degradation modes for the different candidates, so that it is not possible to give many details until the material selection is completed. However, it is envisioned that each of the plans Iisted above will be completed in stages, the initial stage being an umbrella plan that covers the broad aspects of the planned activities. This will be followed by more detailed plans for testing and modeling that will cover particular aspects, such as pitting corrosion, crevice corrosion, or stress corrosion. 


\subsection{History of Netal Barrier Candidate List}

The set of materials selected as candidates for waste package containers in the tuff repository has undergone same evolution over the course of the MWSI project, and it is helpful to briefly review the history of candidate selection.

In late 1982 the NWhSI Project selected a repository horizon in the Topopah Spring member of the Paintbrush Tuff. This horizan lies in the unsaturated zone, well above the permanent water table. Initially, the NWWSI project selected ATSI 304L stainless steel as its reference material and a relatively thin-walled design for its containers. A number of factors contributed to these choices. First of all, it was known that there would be no significant lithostatic or hydrostatic pressure on the containers if emplaced in tuff above the water table. Therefone, thick walls would not be necessary for the prevention of buckling, as is the case for most other proposed deep geologic sites. This situation seemed to lend itself to use of a thin, corrosion resistant material rather than a thicker, corrosion allowance material. Secondly, the Defense Waste Processing Facility at Savannah River had already selected AISI 304L stainless steel as the referenoe material for borosilicate glass pour canisters for its defense waste. It appeared likely at that time (and has since been established as policy by the federal govermment) that defense waste and commercial waste would be enplaced in the same repository. NowisI's initial proposal was thus to use the pour canisters as the metal barriers for deferse waste, and to fabricate containers of the same material (AtSI 304L stainless steel) for the spent fuel. Past experience with austenitic stainless steels in hot air and dry steam emviranents had been very satisfactory, and it appeared that this material would serve well in the unsaturated tuff envirament at temperatures above the boiling point.

The process by which AIST 304L stainless steel was selected as the reference material also resulted in the selection of three other alternatives: AISI 321, AISI 316L, and Alloy 825. These were chosen for their increased resistance to particular types of corrosion, should this be found necessary after more detailed testing, particularly if extensive contact with an aqueous phase was found to be likely, or if the ervirorment turned out to be more severe than anticipated.

This candidate selection process involved the campariscn of 17 cammercial alloys according to the criteria of mechanical properties, weldability, corrosion resistance, and cost. In the absence of enough detailed information to establish relative weights for these four criteria, all four were considered to be equally important. Using available corrosion data, which in same cases was rather sparse, the 17 candidates were ranked and resulted in the selection of the four austenitic alloys ATSI 304L, 321, 3i6L, and alloy B25 for further consideration.

As the project proceeded it became clear that the AISI 304L stainless steel of the borosilicate glass pour canisters would have been subjected to a thermal history that might lead to sensitization of the material to intergranular stress corrosion cracking and that differential thermal expansion during coling of the poured glass and the canister would put the canister walls into hoop tension, aggravating this situation. It was therefore decided to modify the waste package design for the glass waste forms to include an outer container surraunding the pour canister. The thermal history and the stress state in this container could be better controlled, so as to reduce the threat of intergramular stress corrosion cracking. 
In 1984 at the reguest of OCKM, NMMSI began to investigate the feasibility of using copper-base materials for waste package containers. After consultation with the Copper Develogment Association, Inc. and the International Oopper Research Association, Inc., three copper-base materials were selected for further consideration: CDA 102 (oxygen-free copper), CDA 613 (alumimm bronze), and CDA 715 (70-30 copper-nickel). Copper-base materials appeared to offer several potential advantages. First of all, among the available engineering metals, copper alco is able to co-exist thermodynamically with water (under some conditions). The driving force for corrosion and oxidation is thus smaller for copper than for materials such as Fe-Cr-Ni alloys that depend on passive film formation for their corrosion resistance. Localized and stress-assisted forms of corrosion are thus generally less severe for copper-base materials. Evidenoe for survivability of copper materials can be seen in the existence of native copper deposits and in copper and bronze artifacts recovered from the nuins of earlier civilizations.

Another potential actvantage of the copper-base candidates is the simpler microstructures compared to the austenitic materials. Unlike iron, copper has no phase transformations. Thus the phase stability of copper-base materials appears to be of a lesser concern than it is with the iron-base austenitic materials.

After it was decided to include copper-base materials as candidates for further consideration, it became necessary to rechuce the mumber of the other candidates in order to bring the scope of the testing program within the range of available resources. It was decided to eliminate AISI 321 from further onsideration because AISI 316L offers the same benefits as AISI 321, as well as additional ones, so that the range of qualities has been preserved within the austenitic family. This decision leads us to the present six candidates for the metal barrier: AISI 304L and 316L stainless steels, high-nickel austenitic alloy 825, axygen-free copper CA 102, 78 aluminum bronze CAd 613, and 70-30 cogper-nickel CDA 715. Within this field of candidates we thus have materials based un three different metals: iron, nickel (essentially), and copper. We have corrosion-resistant materials, and we also have one (CDA 102) that can be viewed in some respects as a corrosion allowance material (COA 102 would likely be used with a greater wall thickness than the others, anyway, because of its lower strength). 


\subsection{Annotated Reference List}

The content of this SIP camplements material prepared for Chapter 7 (Section 7.4.2) and Chapter 8 (Issue 1.4 and Information leeds 1.4.1-1.4.5) of the SCP that are currently undergoing final review by the NWWSI Project office and the DOE office of Geological Repositories. The material in Chapter $?$ reviewed the choice of candidate materials, preliminary analyses of degradation modes for the materials in the context of the yuca Mountain repository envirarment, and the results of experimental activities (mostly corrosion testing activities). The Chapter 8 material oovered the information flow to and fram other waste package and repository task elements and outlined the work to be done in the next several years. The material in this SIP breaks down this work into discrete activities.

A reference list for some related publications by selected subject areas is given below. This is by no means ar exhaustive source on the subject, but is given as a guide for further reading.

\section{Materiais Selection}

The first paper gives the rationale used to select the first candidate materials (austenitic materials) for the NWSI Project.

E. W. Russell, R. D. Mocright and W. C. O'Neal, "Contairment Barrier Metals for High-Level Waste Packages in a Tuff kepository", Lawrence Iivermore National Iaboratory Report UCRL 53449, (October, 1983).

This work was followed up with additional explanation on corrosion considerations by:

R. D. Mocright, H. Weiss, M. C. Juhas, and R. W. Iogan, "Selection of Candidate Canister Materials for High-Ievel Muclear haste containment in a Tuff Repository", Lawrence Livermore National Laboratory Report UCRL 89988, (November, 1983)

Further reading on principles in selecting stainless steels and nickel-base alloys is found in:

A. J. Sedriks, Corrosion of Stainless Steels, Chapter 2, John Wiley and Sons, New York (1979)

Copper-base materials were added as candidate materials to the NNWSI Project, and the rationale for their addition was discassed in:

R. D. MoCright, "FY-85 status Report on Feasibility Assessment of Copper-Base Waste Package Container Materials in a Tuff Pepository", Lawrence Livermore National Laboratory Report UCID 20509, (September, 1985)

A very informative discussion of many engimeering materials and their potential application as malear waste containers is faund in:

K. Muttall and V. F. Unbanic, "An Assessnent of Materials for Nuclear Fuel Imobilization Containers", Atanic Energy of Canada, Ltd., report AECI-6440, (September, 1981). 


\section{Degradation Modes}

Several good texts exist that discuss corrosion modes and causative factors. The ones that we most frequently refer to are:

M. G. Fontana and N. D. Greene, Corrosion Engineering, and edition, MoGraw-Hill, New York (1977). A new edition of this is ane to be published this year.

L. L. Shreir (editor), Corrosion, Newnes-Buttersworth, London and Boston (1976). This is in many ways, the text on the subject and is very couplete in its treatment of the phencmenology and preventive measures. It is a thick two-volume set; volume 1 is on metal/erviromment reactions and is the cre most applicable to the present work.

An older text, but one which is chock full of information and contains lots of engineering data (most newer texts concentrate more on explaining mechanisms), is:

F. L. Laque and H. R. Copsan, Corrasion Resistance of Ketals and Allovs, and edition, Reinhold Publishing Co., New York, (1963).

\section{Corrosion Test Results}

Same reports fran NMSI-sponsored work that have been used in establishing preliminary analyses on important degradation modes are:

M. C. Juhas, R. D. Mocright, and R. E. Garrison, "Corrosion Behavior of Stressed and Unstressed 304L Specimens in Tuff Repository Erviramental Conditions", Lawrence Livermore National Laboratory Report UCRL 91804, (Novenber, 1984).

R. S. Glass, G. E. Overturf, R. A. Van Konynenbung, and R. D. Nocright, "Gamma Radiation Effects on Corrosion: Electrochenical Mechanisms for the Aqueous Corrosion Processes of Austenitic Stainless steels", porrosion science, vol. 26, p. 577 (August, 1986).

C. F. Acton and R. D. Mocright, "Feasibility Assessment of Copper-Base Waste Package Container Materials in a Tuff Repository", Lawnence Livermore National Laboratory Feport UCID 20847 (September, 1986).

R. E. Hesterman, S. G. Pitman, and J. H. Haberman, "Corrosion Testing of Type 304L Stainless Steel in Tuff Groundwater Ervironments", Pacific Northwest Laboratory Report FNI-5829, INNL Report UCRL-21005 (November, 1987) .

R. D. Hocright, W. G. Halsey, and R. A. Van Konynenburg, "Progress Report on the Results of Testing Advanced Conceptual Design Metal Barrier Materials Under Relevant Envirormental Conditions for a Tuff Repository", IUNL Report UCTD-21044 (Decenber, 1987).

The authoritative source on corrosion test methods is:

W.H. Ailor, Harabook on Cornosion Testing and Evaluation, John Wiley and Sons, New York, (1971). 


\section{Yodeling Activities}

The model of sensitization of stainless steel is discussed in:

T. A. Mozhi, W. A. T. Clark, K. Nishimoto, W. B. Johnson, and D. D. Maodonald, "The Effect of Nitrogen on the Sensitization of AISI 304 Stainless Steel", Corrosion, vol. 41, p.555 (October, 1985).

T. A. Mozhi, H. 5. Betrabet, V. Jagamathan, B. E. Wilde, and W. A. T. Clark, "Thermodynamic Modeling of Sensitization of AISI 304 Stainless Steel Containing Nitrogen", scripta Netallungical, vol. 20, p. 723, (May 1986).

The model of corrosion potentials is discussed in:

M. Unquidi-Hacdonald, D. D. Macionald, and S. Lenhart, Mathematical Models for the Redox Potential and Corcosion Potentials for High-Level Nuclear waste Canisters in Tuff Enviroments", SRI Repart FYD-8292 (February, 1988) (in review). 